\title{
Low-cost technique for resection of a large duodenal lipoma with the aid of a modified polypectomy snare
}

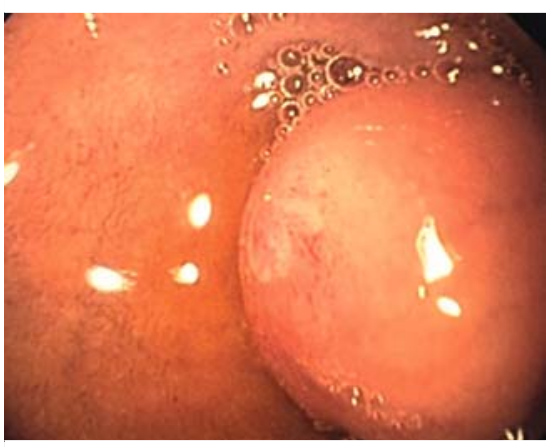

- Fig. 1 Modified polypectomy snare.

A 63-year-old man presented to our hospital with chronic abdominal pain associated with intermittent periods of postprandial vomiting. Esophagogastroduodenoscopy and endoscopic ultrasound confirmed the diagnosis of a lipoma in the second portion of the duodenum. Owing to the unavailability of a therapeutic gastroscope, a conventional polypectomy snare was modified ( $\mathbf{F i g . 1}$ ) in order to be used as a third hand that holds the lipoma, and works as an additional tool in parallel with the scope ( Video 1).

The modification consisted of removing the handle of the manual control device, such that the endoscope could be extracted from the stomach cavity, leaving the snare body inside of it in the same way that a guidewire would be used.

The modified polypectomy snare was placed around the pylorus to act as a "trap." Then, the endoscope tip was advanced through the snare into the duodenum where the lesion was grasped and pulled into the antrum. The modified snare was closed around the pseudopedicle, holding the lipoma in the antrum. The lipoma was resected using a second polypectomy snare, and the mucosal defect was closed with a hemoclip. The patient was discharged home without complications.

A modified polypectomy snare can be a useful accessory tool when a therapeutic endoscope is not available.

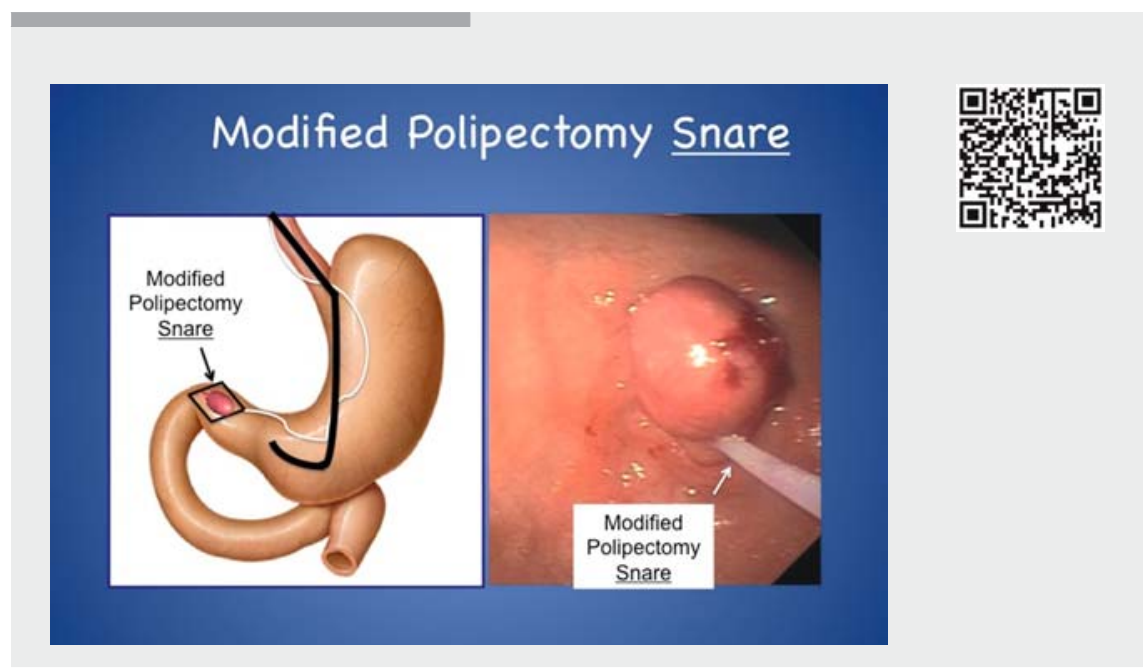

$\checkmark$ Video 1 Resection of a large duodenal lipoma with the aid of a modified polypectomy snare.

Endoscopy_UCTN_Code_TTT_1AO_2AG

Competing interests

None

The authors

Viviana Parra, Javier Preciado, Margarita Huertas, Fanny Acero, Diego Mauricio Aponte, Luis Carlos Sabbagh Division of Gastroenterology, Clínica Universitaria Colombia, Fundación Universitaria Sanitas, Bogotá, Colombia

\section{Corresponding author}

\section{Viviana Parra, MD}

Division of Gastroenterology, Clínica

Universitaria Colombia, Fundación

Universitaria Sanitas, Bogotá, Colombia

Fax: +57-1-6377940

viviparravargas@gmail.com

\section{Bibliography}

DOI https://doi.org/10.1055/s-0043-120265

Published online: 3.11.2017

Endoscopy 2018; 50: E22

(c) Georg Thieme Verlag KG

Stuttgart · New York

ISSN 0013-726X

\section{ENDOSCOPY E-VIDEOS \\ https://eref.thieme.de/e-videos}

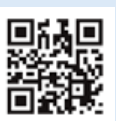

Endoscopy E-Videos is a free access online section, reporting on interesting cases and new

techniques in gastroenterological endoscopy. All papers include a high quality video and all contributions are freely accessible online.

This section has its own submission website at

https://mc.manuscriptcentral.com/e-videos 